\title{
Carotid Baroreceptors in Fetal and Newborn Sheep
}

\author{
C. E. BLANCO, G. S. DAWES, ${ }^{1}$ M. A. HANSON, AND H. B. MCCOOKE \\ Department of Physiology and Biochemistry, University of Reading, Whiteknights, Reading RG6 2AJ, England
}

\begin{abstract}
The responses of single carotid baroreceptor afferents were determined in anaesthetized fetal lambs at 88-113 and 131-144 days gestation, and in newborn lambs 1-8 and 30-40 days old. The baroreceptors discharged in synchrony with the arterial pressure pulse and increased their discharge rate as pressure was raised by compression of the abdominal aorta. When step increases in pressure were applied to the vascularly isolated carotid sinus, baroreceptor discharge increased abruptly and then showed adaptation to a steady state level. Basal mean arterial pressure increased from $\mathbf{4 9 . 1}$ in the young fetuses to 87.5 $\mathrm{mm} \mathrm{Hg}$ in the 30- to 40-day-old lambs without an accompanying increase in basal baroreceptor discharge expressed absolutely or as a function of maximum discharge for each unit. The slope of the steep portion of the stimulus-response curve decreased with gestational age from 7.89 \pm 1.57 (mean $\pm \mathrm{SE}$ ) at 88-113 days gestation to $1.82 \pm$ $0.37 \%$ nerve activity $\cdot \mathrm{mm} \mathrm{Hg}^{-1}$ in the 30 - to 49 -day-old lambs. Dynamic and steady state response curves were determined using step increases in carotid sinus pressure in two fetal lambs of $\mathbf{1 3 5}$ days gestation and two lambs 8 days old. Both the dynamic and the steady state curves were less steep in the older lambs. We conclude that the sensitivity of the carotid baroreceptors is reset as arterial pressure increases throughout the last third of gestation and the first postnatal month. This resetting is seen as a shift to the right of the response curve and a decrease in its slope. Our results suggest that the afferent limb of the baroreflex can be elicited throughout this period, but that its sensitivity decreases with age. (Pediatr Res 24: 342346, 1988)
\end{abstract}

\section{Abbreviations}

$\mathrm{PaO}_{2}$, arterial $\mathrm{PO}_{2}$

$\mathrm{PaCO}_{2}$, arterial $\mathrm{PCO}_{2}$

pHa, arterial pH

iv, intravenous

There are no reported studies of the stimulus-response characteristics of baroreceptor afferents in fetal compared to newborn animals. Biscoe et al. (1) recorded carotid baroreceptor activity in anaesthetized exteriorized fetal sheep at 125-147 days gestational age, and found that it was phasic, in synchrony with the arterial pressure pulse, and was affected by changes in blood

Réceived December 22, 1987; accepted May 10, 1988.

Correspondence Prof. Dr. C. E. Blanco, Department of Neonatology, Academic Hospital Maastricht, P.O. Box 1918, 6201 BX Maastricht, The Netherlands.

Supported by the Medical Research Council. M.A.H. is a Wellcome Trust Senior Lecturer. H.B.M. was supported by the British Heart Foundation.

' Present address Charing Cross Medical Research Centre, Lurgan Avenue, Hammersmith, London W6 8LW, England. pressure. Ponte and Purves (2) made similar observations on the aortic baroreceptors in the fetal lamb. Stimulus-response curves were not determined in either of these studies. For the newborn, the earliest report of baroreceptor discharge is that of Downing (3), who recorded the activity of single and multifiber baroreceptor preparations from the aortic depressor and carotid sinus nerves of rabbits from within $1 \mathrm{~h}$ of birth, finding that they were phasically active and increased their discharge when arterial pressure was raised. Phasic activity of carotid baroreceptors has also been reported for newborn lambs (4), although again stimulus-response curves were not determined.

In contrast to the lack of information about its afferent limb, there have been many studies of the baroreflex in fetal and newborn sheep. The assumption of Bauer (5) and Barcroft (6), that the mean arterial pressure in the newborn is below the threshold pressure for eliciting the baroreflex, could be taken to apply to the fetus, in which the blood pressure is even lower. Evidence in favor of this comes from the work of Ismay et al. (7) who were unable to detect a change in baroreflex sensitivity throughout late gestation using phenylephrine to elevate arterial pressure, but found that sensitivity was less in the fetus than in the adult. Dawes et al. (8) used a variety of techniques and concluded that the sensitivity of the reflex was different with the different methods, but that it was lower in the fetus than in the adult. However, Shinebourne et al. (9) concluded that the sensitivity of the reflex, elicited by inflation of a balloon in the descending aorta, increased through gestation, and Dolan et al. (10) found that it increased from postnatal days 9-14 to 20-27, and again by days 50-70. Maloney et al. (11) compared the sensitivity obtained by using an aortic balloon with that obtained by giving phenylephrine iv. They did not detect a change in sensitivity during gestation, but found that it was greater in the fetus than in the newborn. They discussed the problems of using a pressor agent such as phenylephrine, e.g. direct effects on the myocardium or central nervous system. Finally, Itskovitz et al. (12) examined the stability of arterial blood pressure and heart rate after bilateral section of the carotid sinus and aortic nerves [using the method of Itskovitz and Rudolph (13)] in fetal lambs at 120-136 days gestation or in adult sheep. This procedure did not produce long-term changes in heart rate or arterial pressure, but their variability increased. They concluded that in the fetus the baroreceptors may play a role in regulating the variability of heart rate and arterial pressure.

It may be that in the fetus reflex control of the circulation consists to a greater degree in alterations in regional blood flow (12) rather than changes in heart rate. Therefore we believed that it was essential to conduct a study of the stimulus-response characteristics of single baroreceptor afferents in fetuses at two gestational ages and in newborn and 1-month-old lambs. We have used a method that produces a rise in arterial pressure over several heart beats, similar to that used by previous groups studying the baroreflex. This yields information about the afferent limb of the reflex under these conditions. In addition, we have used a method for applying a step increase in pressure to 
the carotid sinus so that both dynamic and steady state responses can be measured. A preliminary report of some of this work has been published (14).

\section{MATERIALS AND METHODS}

Exteriorized, anaesthetized fetuses. Experiments were performed on 12 pregnant mule-cross breed sheep between either $88-113$ or $131-144$ days after timed mating. They were anaesthetized with $1-2 \%$ halothane in $\mathrm{O}_{2}$ after induction with thiopentone (Intraval, $1 \mathrm{~g}$ iv). The trachea was cannulated and the ewe was artificially ventilated. Catheters were placed in a common carotid artery and an external jugular vein. The ewe was laid on the right flank on a table of adjustable height and an incision about $25 \mathrm{~cm}$ long was made in the midline caudal to the navel. The wall of the uterus was marsupialized to the abdominal wall and an incision about $10 \mathrm{~cm}$ long was made in a region free of caruncles. The fetus was exteriorized and placed on another adjacent table that was heated. Care was taken to avoid stretching the umbilical cord. The fetus and cord were covered with cotton wool, and the cord itself was kept moist with warm saline throughout the experiment. Fetal rectal temperature was maintained at $39 \pm 0.5^{\circ} \mathrm{C}$ with a homeothermic blanket (Bioscience) and supplementary heating lamps. A brachial artery was catheterized for recording of blood pressure (Statham P23 transducer and Devices amplifier), and for taking arterial blood samples of $0.5 \mathrm{ml}$ (blood gases and $\mathrm{pH}$ measured by Instrumentation Laboratory 1302 analyzer). Mean values $( \pm S E)$ for these fetuses were: $\mathrm{PaO}_{2} 18.9 \pm 0.9 \mathrm{~mm} \mathrm{Hg} ; \mathrm{PaCO}_{2} 57.9 \pm 4.5 \mathrm{~mm} \mathrm{Hg}$; $\mathrm{pHa} 7.193 \pm 0.024$. The fetal head was held in the supine position in a stereotaxic frame (David Kopf Instruments, Tujunga, CA). A midline incision was made in the neck, the larynx retracted to the right, and the skin of either side of the incision was pulled up to form a pool filled with warm mineral oil. Using a dissecting microscope, the left carotid sinus nerve was identified (15) and carotid sinus nerve was desheathed and laid on an angled stainless-steel cut close to its junction with the glossopharyngeal nerve. The plate attached to a micromanipulator. Fine strands were dissected from the nerve and hung from one of a pair of stainlesssteel hook electrodes; the other electrode was earthed in close proximity. Neural activity was amplified, filtered, and counted with standard neurophysiological equipment (Neurolog) and displayed on an oscillographic recorder (Medelec); a second channel was used for an electrocardiogram. Records were also made on magnetic tape (Racal Store 7DS), and on a chart recorder (Devices MX4). In the majority of the experiments an increase in arterial blood pressure was produced over several heart beats by direct compression of the abdominal aorta. This procedure produced an increase in baroreceptor discharge that characteristically reached a plateau. The pressure range over which the baroreceptor activity was measured, was $35-106 \mathrm{~mm} \mathrm{Hg}$ for fetuses of 88-113 days; for those of 131-144 days it was 52-136 $\mathrm{mm} \mathrm{Hg}$; for newborns of $<7$ days it was $53-157 \mathrm{~mm} \mathrm{Hg}$; and for those of 30-40 days it was 96-198 mm Hg.

In two fetuses of 135 days gestation baroreceptor responses were determined to step increases in pressure in a vascularly isolated carotid sinus (Fig. 1). In these experiments pressure in the carotid sinus was measured from a catheter inserted via the lingual artery. Another catheter was inserted in a central direction into the external carotid artery. The occipital artery was ligated and a loop of suture was passed around the common carotid artery so that it could be occluded for short periods. When this vessel was occluded, pressure in the carotid sinus fell below 25 $\mathrm{mm} \mathrm{Hg}$. This pressure was still suprathreshold for baroreceptors. A step change in pressure was then produced by forcing blood (drawn from an adult sheep) from a thin-walled rubber balloon into the external carotid artery catheter. The balloon was suspended in a bottle that could be pressurized using a sphygmomanometer and the bottle was held in a water bath at $39^{\circ} \mathrm{C}$. By first pressurizing the bottle and then opening the tap connecting the balloon to the catheter, step increases in carotid sinus pressure of various sizes were produced.

Anaesthetized newborn lambs. Eleven lambs born naturally at 147 days gestation were studied. They were divided into two groups, between 1-8 and 30-40 days old. They were anaesthetized with pentobarbitone $(20-30 \mathrm{mg} / \mathrm{kg}$ intraperitoneally for induction, then $5-10 \mathrm{mg} / \mathrm{kg} \cdot \mathrm{h}^{-1}$ iv) and artificially ventilated with $\mathrm{O}_{2}$-enriched air. Blood gases and $\mathrm{pH}$ for these animals were: $\mathrm{PaO}_{2}>69 \mathrm{~mm} \mathrm{Hg} ; \mathrm{PaCO}_{2} 41.4 \pm 6.3 \mathrm{~mm} \mathrm{Hg}$; and pHa $7.247 \pm$ 0.092 . The dissection of the carotid sinus nerve and the recording methods were as described above. Again, in the majority of experiments an increase in arterial pressure was produced by direct compression of the abdominal aorta. In two lambs 8 days old (one anaesthetized with $2 \%$ halothane in $\mathrm{O}_{2}$, the other with $20-30 \mathrm{mg} / \mathrm{kg}$ pentobarbitone) the method described above for applying step increases in pressure to the carotid sinus was used.

Analysis of baroreceptor sensitivity. For the experiments in which occlusion of the aorta was used to raise pressure, barore-

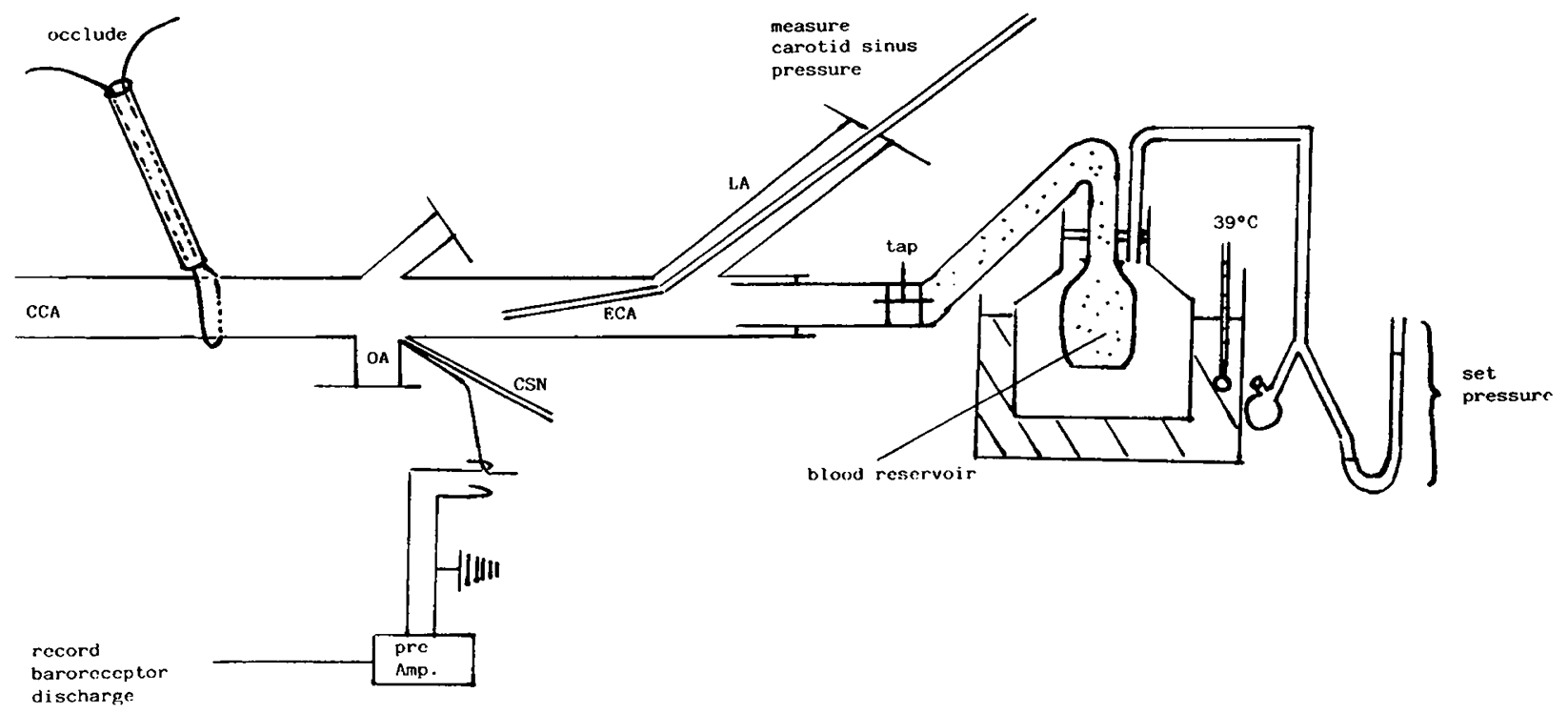

Fig. 1. Method for producing step change in blood pressure into vascularly isolated carotid sinus. Pressure in the reservoir is set with the tap closed. Then the common carotid artery $(C C A)$ is occluded and the tap is opened. Actual pressure in the sinus is measured from a catheter inserted via the lingual artery. $C S N$, carotid sinus nerve; $E C A$, external carotid artery; $L A$, lingual artery; OA, occipital artery. 
ceptor discharge was analyzed on a beat-to-beat basis, taking only the rising limb of the response (Fig. 1) in order to avoid the problems of hysteresis. For each beat analyzed single baroreceptor discharge (identified by the amplitude and shape of the potentials) was counted from visual inspection of the record and expressed as mean discharge in impulses/second using the R-R wave interval. Mean arterial pressure, taken as diastolic pressure plus one-third of the pulse pressure, was plotted against mean discharge to obtain a response curve. The slope of the steep portion of the curve was determined by linear regression using the least squares method, omitting points judged by eye to lie on the plateau. The basal discharge for each unit at the control arterial pressure was determined as a percentage of the maximum frequency of discharge at the plateau of the response curve.

For the experiments in which step increases in carotid sinus pressure were produced, peak baroreceptor discharge $(\mathrm{Hz})$ was taken to represent the dynamic response and the level to which discharge adapted after $30 \mathrm{~s}$ to $1 \mathrm{~min}$ was taken to represent the steady state response. These values were expressed as a percentage of the maximum discharge which each unit could achieve using a large increase in pressure. Percentage maximum discharge was then plotted against the value to which the carotid sinus pressure was increased (Fig. 2). Student's $t$ test for unpaired data was used to compare values between groups of animals. One-way analysis of variance was used for the analysis of the slope of the baroreceptor response in relation to age. Significance was deemed to be reached when $p<0.05$.

\section{RESULTS}

In all animals, regardless of age, carotid baroreceptors were phasically active in synchrony with the arterial pressure pulse and the discharge increased when the arterial pressure was raised (e.g. Fig. 1). The mean discharge at basal arterial pressure varied greatly, some units having only one action potential per heart beat, others up to 15 . This variation was within, as opposed to between, groups of animals. The results are compiled in Table 1. Basal mean arterial blood pressure increased between 88-113 and 131-144 days gestation. However, this increase in mean pressure was not associated with a significant increase in basal baroreceptor discharge, expressed as a percentage of the maximum discharge for each receptor during compression of the abdominal aorta ( $p>0.05$ by unpaired $t$ test). There was not a significant difference in basal mean arterial blood pressure between the fetuses aged 131-144 days gestation and the newborn lambs up to 7 days old; nor was there an increase in basal baroreceptor discharge over this period. Mean arterial pressure was, however, greater in the 30- to 40 -day-old lambs than in those up to 7 days old, but again, there was no significant change in basal discharge. There was not a significant difference in the rate of change of arterial blood pressure which was produced by aortic compression in the four groups of animals (Table 1). There was a significant reduction $(p<0.01$ by one-way analysis of variance) in the slope of the steep portion of the stimulusresponse curve which was, however, related to gestational or postnatal age (Table 1; Fig. 3). In the experiments in which step increases in carotid sinus pressure were used, the slopes of both the dynamic and the steady state sensitivity line appeared less in the 8 days old lambs than in the fetuses of 135 days gestational age (Fig. 4). These data are of course limited and no statistical analysis is appropriate. It was not possible to determine the intercepts on the pressure axis inasmuch as pressure in the carotid sinus did not drop to zero on occlusion of the common carotid artery before the step increase was produced.

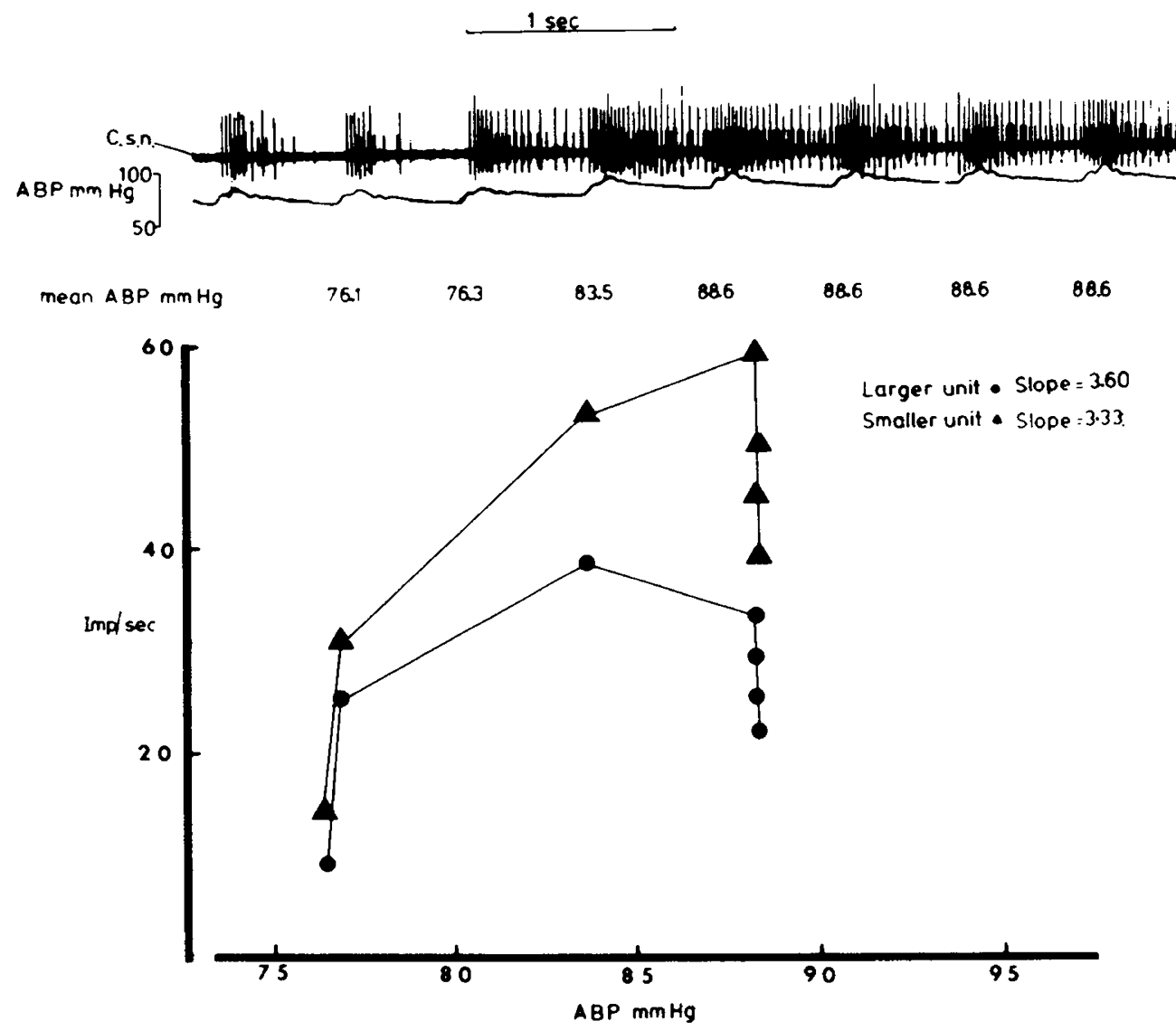

Fig. 2. Top, response of carotid baroreceptors to rise in cephalic arterial pressure produced by compression of the abdominal aorta. Mean arterial pressure for each pulse is shown. Bottom, method for determining response curve during a rise in pressure over several heart beats. For each pulse mean arterial pressure is plotted versus mean discharge. Units with larger and smaller action potentials have been plotted separately. For each response curve the slope is shown. 
Table 1. Mean basal arterial blood pressure, heart rate, mean rate of change of arterial blood pressure (ABP) during occlusion of abdominal aorta, basal carotid baroreceptor activity (\% of maximum response), and slope of steep portion of the response curve before and after birth

\begin{tabular}{|c|c|c|c|c|c|c|c|c|}
\hline $\begin{array}{l}\text { Gestational } \\
\text { age or } \\
\text { postnatal } \\
\text { age (days) }\end{array}$ & $\begin{array}{c}\text { No. of } \\
\text { animals }\end{array}$ & $\begin{array}{c}\text { No. of } \\
\text { units }\end{array}$ & $\begin{array}{c}\text { Heart } \\
\text { rate } \\
\text { (bpm) }\end{array}$ & $\begin{array}{c}\text { Basal mean } \\
\text { arterial blood } \\
\text { pressure }(\mathrm{mm} H \mathrm{Hg}) \\
(\overline{\mathrm{x}} \pm \mathrm{SE})\end{array}$ & $\begin{array}{l}\text { Mean ABP } \\
(\mathrm{mm} \mathrm{Hg} / \mathrm{s})\end{array}$ & $\begin{array}{c}\text { Max discharge } \\
(\mathrm{Hz}) \\
(\overline{\mathrm{x}} \pm \mathrm{SE}) \\
\end{array}$ & $\begin{array}{c}\text { Basal baroreceptor } \\
\text { discharge } \\
\text { (\% of maximum) } \\
(\overline{\mathrm{x}} \pm \mathrm{SE})\end{array}$ & $\begin{array}{c}\text { Slope of } \\
\text { steep portion } \\
(\% \mathrm{~mm} \\
\left.\mathrm{Hg}^{-1}\right) \\
(\overline{\mathrm{x}} \pm \mathrm{SE})\end{array}$ \\
\hline $88-113$ & 6 & 19 & $163 \pm 13$ & $49.1 \pm 10.1$ & $9.39 \pm 1.7$ & $58.9 \pm 8.0$ & $23.5 \pm 5.1$ & $7.89 \pm 1.57$ \\
\hline $131-144$ & 5 & 13 & $141 \pm 19$ & $74.4 \pm 1.7$ & $4.36 \pm 0.8$ & $49.2 \pm 6.1$ & $36.2 \pm 8.3$ & $5.14 \pm 1.06$ \\
\hline 7 & 5 & 12 & $245 \pm 15$ & $71.8 \pm 3.4$ & $8.98 \pm 1.55$ & $53.4 \pm 8.5$ & $46.9 \pm 4.4$ & $3.29 \pm 0.61$ \\
\hline $30-40$ & 4 & 8 & $150 \pm 12$ & $87.5 \pm 10.2$ & $7.87 \pm 0.59$ & $54.2 \pm 10.6$ & $\begin{array}{c}36.0 \pm 3.6 \\
p>0.05\end{array}$ & $\begin{array}{c}1.82 \pm 0.37 \\
p<0.01\end{array}$ \\
\hline
\end{tabular}

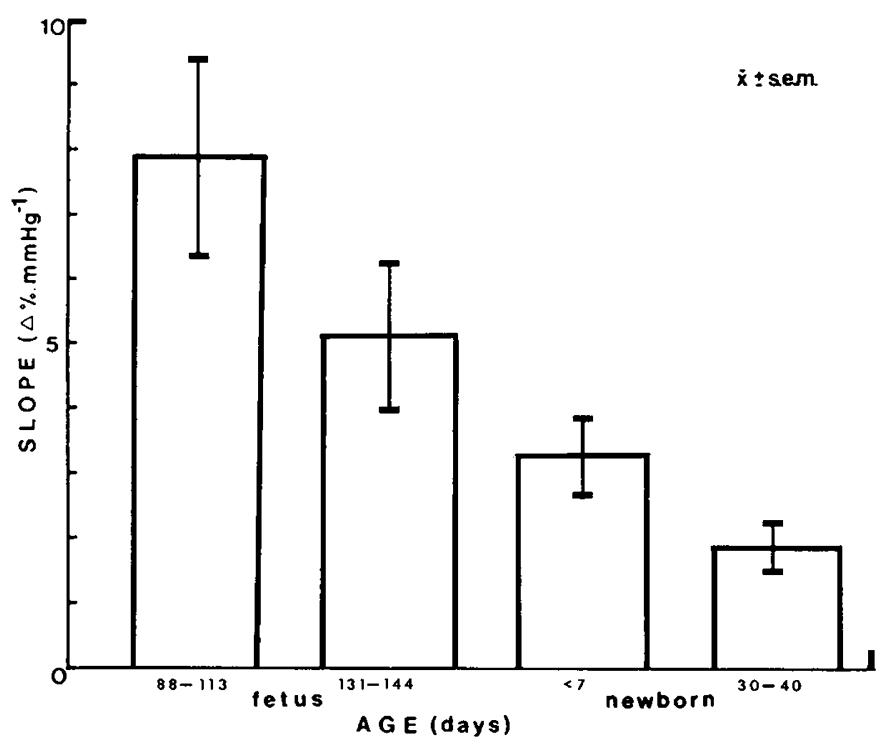

Fig. 3. The decrease in the sensitivity of the afferent limb of the baroreflex (slope) with gestational and postnatal age.

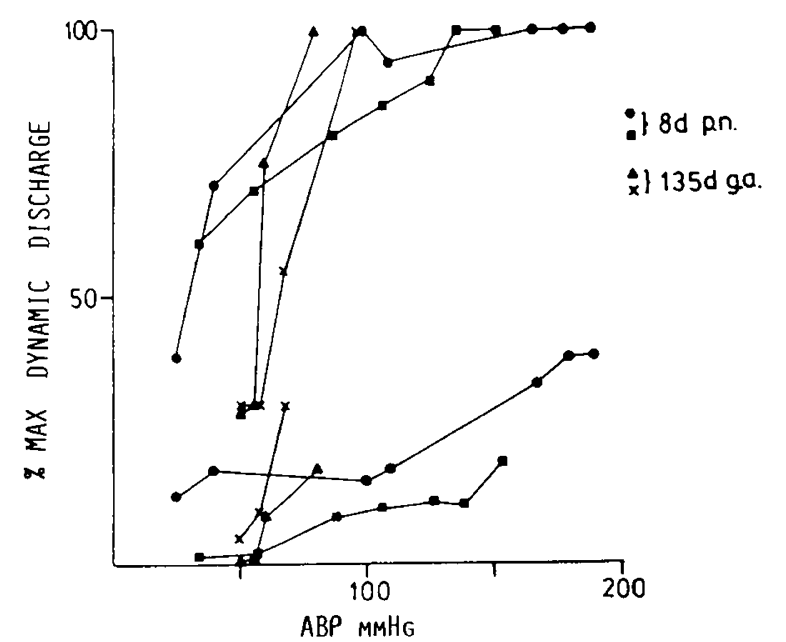

Fig. 4. Baroreceptor response curves of two fetuses of 135 days gestational age ( g.a.) and two lambs of postnatal age (p.n.) 8 days to various step increases in carotid sinus pressure. Upper lines show the maximum (dynamic) responses and the lower lines of the steady state (adapted) responses. $A B P$, arterial blood pressure.

\section{DISCUSSION}

In this study, as in previous ones $(1,3,4,11,15)$, we have observed phasic activity of baroreceptors despite an increase in mean arterial pressure during late gestation and after birth. These studies have necessarily to be performed on anaesthetized fetuses or newborn lambs. It is likely that in the fetuses the procedure produced an increase in arterial pressure that is progressive with time after exteriorization. However, because single carotid baroreceptor fibers are comparatively easy to dissect, the experiments were performed within $1 \mathrm{~h}$ of exteriorization, at a time when the mean arterial pressure was within the range reported by Dawes et al. (8) for the unanaesthetized fetus in utero. In addition, we have used transient occlusion of the abdominal aorta rather than injection of catecholamines to raise arterial pressure: this test does not produce a prolonged increase in peripheral resistance and can be repeated at short intervals. This permits the study of several single afferent fibers in each animal.

We used halothane in our fetal experiments and pentobarbitone in the newborn experiments. Halothane has been reported to excite arterial baroreceptors (16). However, we cannot account for the differences in baroreceptor sensitivity between the four groups of animals merely on the basis of differences in anaesthesia, since the sensitivity was different in the two groups of fetuses and in the two groups of lambs, despite the fact that they received the same anesthesia.

In any work involving recording form single nerve fibres one cannot exclude unconscious selection of the fibres studied. We have made efforts to avoid dissecting strands of the nerve in a fixed anatomical order and to tease each strand that clearly contained baroreceptor activity until a single unit was obtained. In this way we avoided studying only those afferents with large action potentials, presumably myelinated fibers. However, single unmyelinated fibers are hard to dissect and the signal-to-noise ratio can be low. We ruined many strands in the search for single fibers and cannot claim that our study is an exhaustive one, especially because the degree of myelination of the carotid sinus nerve is likely to change over the age range we have used.

Despite the reservations above, a crucial result to emerge from this work is that baroreceptor afferents with a wide range of discharge at basal arterial blood pressure were all phasically active and increased discharge as pressure was raised. Moreover, basal discharge, expressed as percentage of maximum discharge for each unit, did not change significantly despite the increase in mean arterial blood pressure with gestational or postnatal age. This indicates that the baroreceptors reset during this period in the lamb, as found by Downing (3) for the newborn rabbit.

Apart from the shift of the response curve to the right with age, we have also found a significant decrease in the slope of the steep portion of the curve with age (Table 1; Fig. 3). Thus, the sensitivity of the baroreceptors to an increase in pressure is reduced between 90 days gestation and 1 month postnatal age. We do not know the mechanism of this resetting or if it is similar to that seen in adult animals $(17,18)$ or man (19). Our studies using step changes in carotid sinus pressure suggest that both dynamic and steady-state sensitivity decreased from fetal to postnatal life. Our aim was, however, primarily to gain information about the changes in afferent discharge that occur during slower increases in pressure, as in the foregoing studies of the baroreflex. 
On the basis of the baroreceptor afferents alone, one would predict that the baroreflex should be elicitable in the fetal and newborn lamb, but that its sensitivity should decrease with age. The efferent limb of the reflex is functional in the fetal sheep from 60 days gestation since Born et al. (20) showed that stimulation of the peripheral cut end of the vagus caused bradycardia at this age. Yet as discussed earlier, there is no agreement about the reflex on the basis of the changes in heart rate elicited by raising arterial pressure. It may be that in the fetus reflex control of the circulation consists to a greater degree in alterations in regional blood flow (12) rather than changes in heart rate. But another important consideration must be of central nervous influences that might modify the efferent limb of the reflex. A close parallel is provided by the chemoreflex effects on breathing, for while the carotid chemoreceptors are active and responsive to natural stimuli in the fetus (15), hypoxia produces a cessation of fetal breathing movements and this involves a suprapontine descending inhibitory mechanism. This idea is supported by the finding of Dawes et al. (21) that the sensitivity of the baroreflex is increased in fetal lambs with brainstem transection at about the level of the hypothalamus.

At present we do not know the mechanisms underlying the changes in baroreceptor sensitivity that we have reported; mechanisms similar to those producing baroreceptor resetting during development in the spontaneously hypertensive rat as described by Andresen and coworkers (22-24) may play a role. Further work is needed to elucidate the mechanisms operating to modify the gain of the baroreflex in the fetus and newborn.

\section{REFERENCES}

1. Biscoe TJ, Purves MJ, Sampson SR 1969 Types of nervous activity which may be recorded from the carotid sinus nerve on the sheep foetus. $J$ Physiol 202:1-24

2. Ponte J, Purves MJ 1973 Types of afferent nervous activity which may be measured in the vagus nerve of the sheep foetus. J Physiol 229:51-76

3. Downing SE 1960 Baroreceptor reflexes in newborn rabbits. J Physiol 150:201213

4. Biscoe TJ, Purves MJ 1967 Carotid body chemoreceptor activity in the newborn lamb. J Physiol 190:443-454
5. Bauer DJ 1939 Vagal reflexes appearing in the rabbit at different ages. J Physiol 95:187-202

6. Barcroft J 1946 Researches on Pre-Natal Life. Blackwell, Oxford

7. Ismay MJA, Lumbers ER, Stevens AD 1979 The action of angiotensin II on the baroreflex response of the conscious ewe and the conscious fetus. J Physiol 288:467-479

8. Dawes GS, Johnston BM, Walker DW 1980 Relationship of arterial pressure and heart rate in fetal, newborn and adult sheep. J Physiol 309:405-417

9. Shinebourne EA, Vapaavuori EK, Williams RL, Heymann MA, Rudolph AM 1972 Development of baroreflex activity in unanaesthetized fetal and neonatal lambs. Circ Res 31:710-718

10. Dolan LM, Kaiser DL, Peach MJ, Wright EM Jr, Carey RM 1983 Relationship of baroreceptor reflex (BBR) activity to postnatal hemodynamic changes. Pediatr Res 17:264 (abstr)

11. Maloney JE, Cannata J, Dowling MH, Else W, Ritchie B 1977 Baroreflex activity in conscious fetal and newborn lambs. Biol Neonate 31:340-350

12. Itskovitz J, LaGamma EF, Rudolph AM 1983 Baroreflex control of the circulation in chronically instrumented fetal lambs. Circ Res 52:589-596

13. Itskovitz J, Rudolph AM 1982 Denervation of arterial chemoreceptors and baroreceptors in fetal lambs in utero. Am J Physiol 242:H916-H920

14. Blanco CE, Dawes GS, Hanson MA, McCooke HB 1985 Studies of carotid baroreceptor afferents in fetal and newborn lambs. In: Jones CT, Nathanielsz PW (eds) The Physiological Development of the Fetus and Newborn. Academic Press, London, pp 595-598

15. Blanco CE, Dawes GS, Hanson MA, McCooke HB 1984 The response to hypoxia of arterial chemoreceptors in fetal sheep and newborn lambs. $J$ Physiol 351:25-37

16. Biscoe TJ, Millar RA 1964 The effect of halothane on carotid sinus baroreceptor activity. J Physiol 173:24-37

17. Brown AM 1980 Receptors under pressure. An update on baroreceptors. Circ Res 46:1-10

18. Coleridge HM, Coleridge JCG, Poore ER, Roberts AM, Schultz HD 1984 Aortic wall properties and baroreceptor behaviour at normal arterial pressure and in acute hypertensive resetting in dogs. J Physiol 350:309-326

19. Sleight $P 1980$ Arterial Baroreceptors and Hypertension. Oxford University Press, Oxford,

20. Born GVR, Dawes GS, Mott JC 1956 Oxygen lack and anatomic control of the foetal circulation in the lamb. J Physiol 134:149-166

21. Dawes GS, Gardner WN, Johnston BM, Walker DW 1983 Breathing in fetal lambs: the effect of brain stem section. J Physiol 335:525-553

22. Andresen MC, Krauhs JM, Brown AM 1978 Relationship of aortic wall and baroreceptor properties during development in normotensive and spontaneously hypertensive rats. Circ Res 43:728-738

23. Andresen MC, Kuraoka S, Brown AM 1980 Baroreceptor function and changes in strain sensitivity in normotensive and spontaneously hypertensive rats. Circ Res 47:821-828

24. Andresen MC, Brown AM 1980 Baroreceptor function in spontaneously hypertensive rats. Effect of preventing hypertension. Circ Res 47:829-834 